\title{
OPTIMALISASI PERSEDIAAN PRODUK SODIUM HYPOCHLORITE MENGGUNAKAN PENDEKATAN LINIER PROGRAMMING
}

\author{
Rusman Zaenal Abidin*, Sumarsono Sudarto, Sawarni Hasibuan \\ Program Studi Magister Teknik Industri, Fakultas Teknik, Universitas Mercubuana \\ Email: rusman.abidin@gmail.com, sumarsono@elite-tutors.co.id, sawarni02@mercubuana.ac.id
}

Artikel masuk : 01-11-2020

Artikel direvisi : 10-12-2020

Artikel diterima : 15-12-2020

*Penulis Korespondensi

\begin{abstract}
Abstrak - Pembatasan angkutan produk pada masa hari raya Idul Fitri merupakan kendala yang sering dialami oleh perusahaan yang produknya mempunyai masa kadaluarsa yang pendek. Perencanaan produksi yang kurang tepat dapat berdampak pada proses dekomposisi yang menambah biaya produksi. Penelitian ini bertujuan untuk mengoptimalkan perencanaan persediaan pada masa setelah hari raya Idul Fitri dengan menggunakan metode linier programming. Penelitian ini berfokus pada perencanaan persediaan produk sodium hypochlorite yang mempunyai lifetime sebentar. Metode linier programming yang digunakan adalah metode simpleks yang dapat mengakomodasi kendala-kendala yang terjadi. Hasil penelitian menunjukkan untuk meminimalkan biaya produksi produk sodium hypochlorite maka diperlukan 180 ton yang melalui proses dekomposisi dan 720 ton disimpan dalam tangka dan 180 ton yang diproses kembali. Hasil tersebut menunjukkan tidak memerlukan fasilitas pembuatan tangki baru yang memerlukan biaya yang tidak sedikit. Implementasi linier programming dapat membantu mengambil keputusan yang tepat berdasarkan kendala-kendala yang terjadi pada suatu proses persediaan produk.
\end{abstract}

Kata kunci: Linier Programming; Perencanaan Persediaan; Optimasi

\begin{abstract}
Restrictions on product transportation during Eid al-Fitr are an obstacle that is often experienced by companies whose products have a short shelf life. Inaccurate production planning can have an impact on the decomposition process, which increases production costs. This study aims to optimize inventory planning after Eid al-Fitr by using the linear programming method. This research focuses on planning a sodium hypochlorite product inventory that has a short lifetime. The linear programming method used is the simplex method, which can accommodate the constraints that occur. The results showed that in order to minimize the production cost of sodium hypochlorite, 180 tons were required to go through the decomposition process, and 720 tons were stored in tanks, and 400 tons were reprocessed. These results indicate that it does not require a new tank manufacturing facility, which requires a lot of money. Linear programming implementation can help make the right decisions based on the constraints in a product inventory process.
\end{abstract}

Keywords: Linear Programming; Inventory Planning; Optimization

\section{PENDAHULUAN}

Salah satu strategi meningkatkan profit perusahaan adalah dengan memaksimalkan pemilihan pembuatan produk berdasarkan kebutuhan pasar di lapangan. Proses perencanaan dan penjadwalan menjadi proses yang penting dalam manufaktur (Wassick et al., 2012) untuk dapat membuat produk sesuai dengan kebutuhan pasar. Perencanaan produksi yang baik juga akan meminimalkan kerugian perusahaan terkait dengan produk yang tidak laku atau kadaluwarsa.

Sebuah perusahaan kimia di daerah Cilegon merupakan salah satu perusahaan yang memproduksi $\mathrm{Cl} 2$ dan $\mathrm{NaOH}$ di Indonesia. Selain itu, Perusahaan ini memproduksi $\mathrm{NaClo}, \mathrm{HCl}$, Ethylene Dichloride (EDC), Vinyl Chloride 
Monomer (VCM) dan Polyvinyl Chloride (PVC). Salah satu produk sampingan reaksi klorin (Cl2) dengan soda api $(\mathrm{NOH})$ yang diproduksi di Pabrik Chol-Alkali (Pabrik CA), Pabrik CA1, CA2 dan $\mathrm{CA} 3$ adalah sodium hipokorit ( $\mathrm{NaClo}$ ) dengan kapasitas produksi 150 ton per sehari, hanya 15 ton yang digunakan kembali untuk proses produksi dan sisanya dijual. Permasalahan yang muncul adalah fasilitas tangki penyimpanan di pabrik CA memiliki 12 tangki penyimpanan dengan kapasitas masing-masing 80 ton, namun hanya 10 tangki yang digunakan sedangkan 2 tangki sisanya digunakan sebagai penyangga.

Setiap tahun khususnya pada hari raya Idul Fitri dan jika ada libur panjang misalnya jumlah hari libur terbanyak yang diambil yaitu 15 hari (-7 hari $\mathrm{H}$ dan +7 ) maka produk tidak boleh dikirim ke pelanggan. karena peraturan pemerintah yang membatasi transportasi pada hari libur panjang besar. Kementerian Perhubungan (Kemenhub) akan membatasi angkutan truk yang melintasi jalan tol pada puncak mudik Lebaran 2019. Pembatasan ini berlaku untuk semua jalan tol dan jalan nasional di Indonesia. Berdasarkan Peraturan Menteri Perhubungan Nomor 37 Tahun 2019 tentang Penataan Lalu Lintas Masa Angkutan Lebaran 2019, Kementerian Perhubungan diberlakukan pembatasan operasional mobil barang dan penutupan unit penimbangan kendaraan bermotor. Kendaraan terbatas meliputi, gerbong barang dengan tiga as roda atau lebih, gerbong barang dengan kereta api dan trailer terpasang. Adanya peraturan pemerintah membuat perusahaan harus membuat strategi penjadwalan produksi untuk meminimalkan kerugian yang dialami. Kerugian tersebut antara lain terjadinya proses dekomposisi adalah produk jadi yang dikembalikan ke proses karena produk tidak bisa dikirim ke konsumen.

Salah satu langkah untuk mengoptimalkan perencanaan persediaan dengan adanya beberapa kendala adalah menggunakan Linier Programming. Metode ini mempunyai konsep memaksimalkan atau meminimumkan suatu tujuan berdasarkan kendala yang terjadi (Stapleton et al., 2003). Linier Programming mampu digunakan dengan banyak variabel sehingga fungsi tujuan dapat di fleksibelkan sesuai dengan berbagai kemungkinan yang terjadi (Supriyadi et al., 2017). Beberapa riset menunjukkan implementasi metode ini mampu mengoptimalkan tingkat hasil produksi (Basriati, 2018; Saryoko, 2016), keuntungan (Aprilyanti et al., 2018; Kelvin and Jobiliong, 2015; Wulandari et al., 2019) maupun perencanaan produksi (Livia, 2017; Wulandari et al., 2019). Penelitian ini bertujuan untuk mengoptimalkan persediaan produk sodium hypochlorite dalam menghadapi pasca hari raya berdasarkan kendala-kendala yang terjadi. Hasil metode ini diharapkan mampu mengurangi produk yang mengalami dekomposisi akibat tidak bisa dikirim ke konsumen.

\section{METODE PENELITIAN}

Penelitian ini menggunakan data primer berdasarkan hasil yang diperoleh dari perusahaan. Perhitungan Linier Programming dengan menggunakan metode simpleks untuk menghasilkan perbandingan total biaya yang paling kecil. Metode simpleks melakukan standarisasi model dengan mengubah fungsi kendala ke bentuk persamaan (Gultom et al., 2013).

Langkah-langkah penyelesaian dengan metode simpleks (Hasmi, 2018; Rois, 2018; Sitinjak, 2006) adalah:

1. Memeriksa kelayakan tabel dengan cara nilai solusi tidak ada yang bernilai negatif.

2. Menentukan kolom pivot dengan cara melihat koefisien fungsi tujuan berdasarkan tujuan fungsi. Kolom pivot akan mempunyai koefisien paling negatif jika fungsi tujuannya adalah fungsi maksimasi. Kolom pivot akan mempunyai koefisien positif terbesar jika fungsi tujuannya adalah fungsi minimasi.

3. Menentukan baris pivot dengan langkah membagi nilai solusi dengan nilai kolom pivot yang terpilih, Baris pivot yang terpilih adalah baris yang mempunyai rasio pembagian terkecil.

4. Menentukan elemen pivot yaitu nilai yang terletak pada perpotongan baris dan kolom pivot.

5. Membuat tabel simpleks dengan langkah pertama adalah membentuk nilai baris pivot baru. Baris pivot baru adalah hasil pembagian baris pivot lama dengan elemen pivot yang terpilih. Nilai baris baru lainnya adalah hasil substitusi nilai kolom pivot baris yang bersangkutan dengan baris pivot baru.

6. Memeriksa keoptimalan tabel simpleks dengan cara melihat hasil koefisien fungsi tujuan. Hasil dikatakan optimal jika nilai $Z$ sesuai dengan koefisien fungsi. Jika nilai tujuan ( $Z$ ) belum sama maka dilakukan penentuan kolom pivot lagi seperti pada langkah 2 sampai mendapatkan nilai yang optimal.

\section{HASIL DAN PEMBAHASAN}

Kebijakan sistem transportasi angkutan pada masa hari raya Idul Fitri membuat perusahaan memerlukan beberapa strategi agar sistem persediaan perusahaan dapat optimal. Kebijakan pemerintah ini juga berdampak pada perusahaan kimia yang mempunyai alternatif mendekomposisi produk atau membuat fasilitas baru (Gambar 1). 


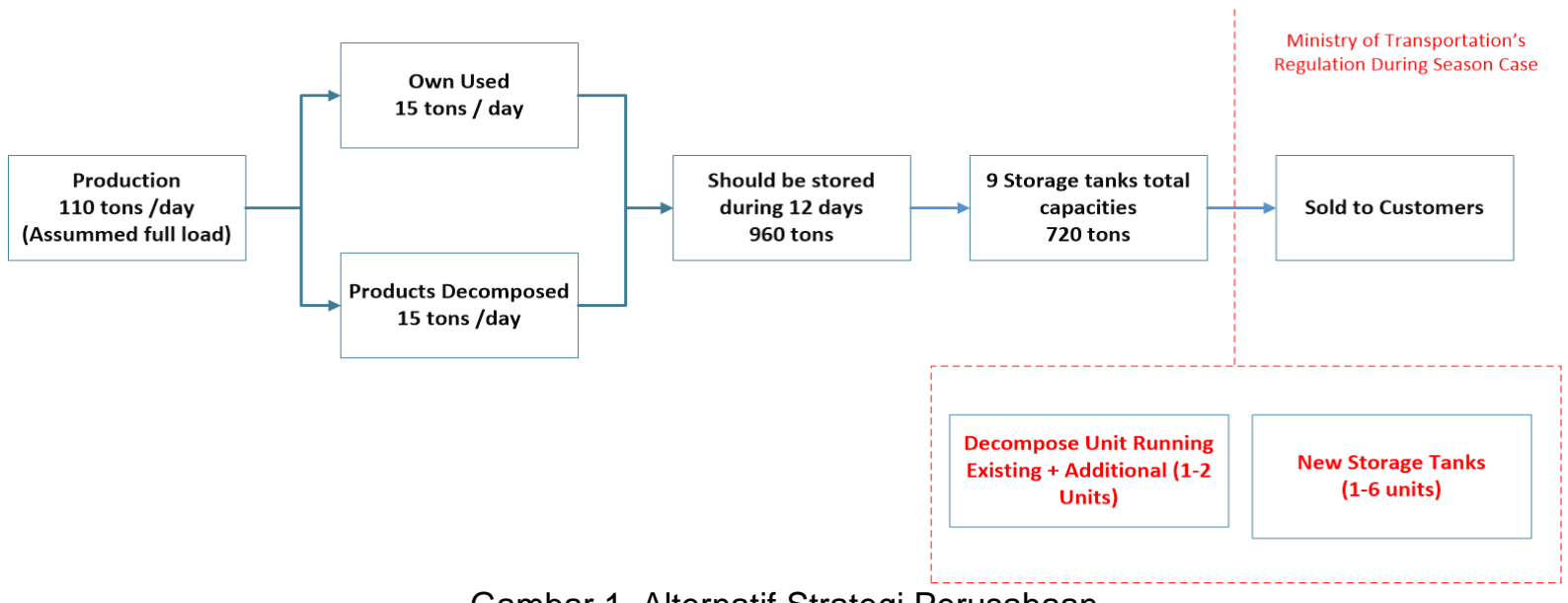

Gambar 1. Alternatif Strategi Perusahaan

Dampak dari kebijakan tersebut, perusahaan mempunyai dua alternatif yaitu melakukan dekomposisi produk/produk dikembalikan ke proses yang meningkatkan biaya produksi atau membuat fasilitas baru yang mempunyai nilai investasi yang sangat besar. Aktivitas produksi sodium hypochlorite $(\mathrm{NaClO})$ per hari adalah 110 ton/hari, namun yang digunakan hanya 15 ton per hari, sehingga sisanya perlu disimpan dalam storage untuk dijual ke pelanggan (customers). Saat ini perusahaan mempunyai 9 tangki dengan kapasitas maksimum 80 ton dan satu decompose dengan kapasitas 15 ton. Berdasarkan data tersebut, maka perusahaan tidak akan mampu menampung keseluruhan produk selama 9 hari kedepan, meskipun telah melakukan decompose secara maksimal. Dengan menggunakan pengendalian inventori seperti itu perusahaan masih memiliki sisa 180 ton $\mathrm{NaClO}$ lagi yang perlu dipertimbangkan. Walaupun produk yang perlu disimpan memiliki kuantitas yang tetap yaitu 80 ton per hari, dengan decompose maksimum 15 ton per harinya masih belum dapat menampung keseluruhan dari produk. Pada hari ke 10 tangki sudah tidak dapat menampung produk lagi dan pada akhirnya di hari berikutnya tangki akan kelebihan kapasitas dan produk tidak dapat ditampung lagi.

Pada saat ini perusahaan telah memiliki 1 fasilitas decompose dengan kapasitas maksimum per hari adalah 15 ton. Kemudian perusahaan juga saat ini telah memiliki 9 tangki storage yang artinya jumlah ini adalah jumlah minimal tangki yang dapat diusulkan nanti untuk manajemen inventori selama Pasca lebaran season case (9 hari). Biaya penyimpanan dalam decompose sebesar \$80/ton dan \$2.ton pada penyimpanan produk di tangki (Tabel 1). Kapasitas maksimum tangki selama 12 hari adalah 720 ton dan 540 ton ada decompose (Tabel 2). Perusahaan juga mempunyai kebijakan untuk memproses produk kembali dengan kapasitas 10 ton/hari.

Tabel 1. Manajemen Inventori

\begin{tabular}{lc}
\hline $\begin{array}{c}\text { Manajemen } \\
\text { Inventori }\end{array}$ & Biaya/ton (\$) \\
\hline Decompose & 38 \\
Tangki & 2 \\
Reprocessed & 50 \\
\hline
\end{tabular}

Tabel 2. Kapasitas Maksimum Fasilitas

\begin{tabular}{lccc}
\hline Fasilitas & $\begin{array}{c}\text { Kapasitas } \\
\text { Pasang (unit) }\end{array}$ & $\begin{array}{c}\text { Kapasitas } \\
\text { Maksimum/u } \\
\text { nit (ton) }\end{array}$ & $\begin{array}{c}\text { Kapasitas } \\
\text { Maksimum } \\
\text { 12 hari (ton) }\end{array}$ \\
\hline Decompose & 1 & 15 & 180 \\
Tangki & 9 & 80 & 720 \\
Reprocessed & - & 40 & 480 \\
\hline
\end{tabular}

Berdasarkan kendala yang ada, penelitian ini bertujuan untuk meminimalkan biaya persediaan berdasarkan kendala-kendala yang ada. Model matematika dari fungsi tujuan ini adalah $\mathrm{Z}=38 \mathrm{X} 1+2 \mathrm{X} 2+50 \mathrm{X} 3$

Kendala $\mathrm{X} 1+\mathrm{X} 2+\mathrm{X} 3=1140$

$\begin{array}{ll}X 1 & \leq 180 \\ X 2 & \geq 80 \\ X 2 & \leq 720 \\ X 3 & \geq 40 \\ X 3 & \geq 480\end{array}$

$\mathrm{X} 1, \mathrm{X} 2 \geq 0$

Model matematika tersebut diolah dengan menggunakan bantuan software POM QM for windows versi 5 untuk mendapatkan solusi optimal meminimalkan biaya yang ditanggung perusahaan. Dari pengolahan tersebut didapat dengan memaksimalkan kapasitas tangki sebesar 720 ton, decompose sebesar 180 ton dan $R e$ processed sebanyak 180 ton dengan biaya sebesar \$20280 (Table 3). 
Tabel 3. Literasi Linier Programming

\begin{tabular}{|c|c|c|c|c|c|c|c|c|c|c|c|c|c|}
\hline $\mathrm{Cj}$ & $\begin{array}{c}\text { Basic } \\
\text { Variables }\end{array}$ & $\begin{array}{l}\text { Qua } \\
\text { ntity }\end{array}$ & $\begin{array}{l}38 \\
X 1\end{array}$ & $\begin{array}{c}2 \\
\times 2\end{array}$ & $\begin{array}{l}50 \\
X 3\end{array}$ & $\begin{array}{c}0 \\
\text { artfcl } \\
1\end{array}$ & $\begin{array}{c}0 \\
\text { slack } \\
2\end{array}$ & $\begin{array}{c}0 \\
\text { artfcl } \\
3\end{array}$ & $\begin{array}{c}0 \\
\text { surplus } \\
3\end{array}$ & $\begin{array}{c}0 \\
\text { slack } \\
4\end{array}$ & $\begin{array}{c}0 \\
\text { artfcl } \\
5\end{array}$ & $\begin{array}{c}0 \\
\text { surplus } \\
5\end{array}$ & $\begin{array}{c}0 \\
\text { slack } \\
6\end{array}$ \\
\hline \multicolumn{14}{|c|}{$\begin{array}{l}\text { Phase } 1 \\
\text { Iteration } 1\end{array}$} \\
\hline 1 & artfcl 1 & 1.140 & 1 & 1 & 1 & 1 & 0 & 0 & 0 & 0 & 0 & 0 & 0 \\
\hline 0 & slack 2 & 180 & 1 & 0 & 0 & 0 & 1 & 0 & 0 & 0 & 0 & 0 & 0 \\
\hline 1 & artfcl 3 & 80 & 0 & 1 & 0 & 0 & 0 & 1 & -1 & 0 & 0 & 0 & 0 \\
\hline 0 & slack 4 & 720 & 0 & 1 & 0 & 0 & 0 & 0 & 0 & 1 & 0 & 0 & 0 \\
\hline 1 & artfcl 5 & 40 & 0 & 0 & 1 & 0 & 0 & 0 & 0 & 0 & 1 & -1 & 0 \\
\hline \multirow[t]{3}{*}{0} & slack 6 & 480 & 0 & 0 & 1 & 0 & 0 & 0 & 0 & 0 & 0 & 0 & 1 \\
\hline & zj & 1.260 & -1 & -2 & -2 & 1 & 0 & 1 & 1 & 0 & 1 & 1 & 0 \\
\hline & cj-zj & & 1 & 2 & 2 & 0 & 0 & 0 & -1 & 0 & 0 & -1 & 0 \\
\hline . & & $\dot{.}$ & $\dot{.}$ &. & $\dot{.}$ &. &. &. &. & &. &. & $\cdot$ \\
\hline Iteration 6 & . & . & . & . & . & . & . & . & . & & . & . & . \\
\hline 0 & surplus 5 & 200 & 0 & 0 & 0 & 1 & -1 & 0 & 0 & -1 & -1 & 1 & 0 \\
\hline 0 & $\mathrm{X} 1$ & 180 & 1 & 0 & 0 & 0 & 1 & 0 & 0 & 0 & 0 & 0 & 0 \\
\hline 0 & $\mathrm{x} 2$ & 720 & 0 & 1 & 0 & 0 & 0 & 0 & 0 & 1 & 0 & 0 & 0 \\
\hline 0 & surplus 3 & 640 & 0 & 0 & 0 & 0 & 0 & -1 & 1 & 1 & 0 & 0 & 0 \\
\hline 0 & $\mathrm{X} 3$ & 240 & 0 & 0 & 1 & 1 & -1 & 0 & 0 & -1 & 0 & 0 & 0 \\
\hline \multirow[t]{3}{*}{0} & slack 6 & 240 & 0 & 0 & 0 & -1 & 1 & 0 & 0 & 1 & 0 & 0 & 1 \\
\hline & zj & 0 & 0 & 0 & 0 & 2 & 0 & 2 & 0 & 0 & 2 & 0 & 0 \\
\hline & cj-zj & & 0 & 0 & 0 & -1 & 0 & -1 & 0 & 0 & -1 & 0 & 0 \\
\hline \multicolumn{14}{|l|}{ Phase 2} \\
\hline 0 & surplus 5 & 200 & 0 & 0 & 0 & 1 & -1 & 0 & 0 & -1 & -1 & 1 & 0 \\
\hline 38 & $\mathrm{X} 1$ & 180 & 1 & 0 & 0 & 0 & 1 & 0 & 0 & 0 & 0 & 0 & 0 \\
\hline 2 & $\mathrm{X} 2$ & 720 & 0 & 1 & 0 & 0 & 0 & 0 & 0 & 1 & 0 & 0 & 0 \\
\hline 0 & surplus 3 & 640 & 0 & 0 & 0 & 0 & 0 & -1 & 1 & 1 & 0 & 0 & 0 \\
\hline 50 & $\mathrm{X} 3$ & 240 & 0 & 0 & 1 & 1 & -1 & 0 & 0 & -1 & 0 & 0 & 0 \\
\hline \multirow[t]{3}{*}{0} & slack 6 & 240 & 0 & 0 & 0 & -1 & 1 & 0 & 0 & 1 & 0 & 0 & 1 \\
\hline & zj & 20.280 & 38 & 2 & 50 & -50 & 12 & 0 & 0 & 48 & 0 & 0 & 0 \\
\hline & cj-zj & & 0 & 0 & 0 & 50 & -12 & 0 & 0 & -48 & 0 & 0 & 0 \\
\hline
\end{tabular}

Optimalisasi tangki merupakan solusi yang optimal karena mempunyai biaya yang terkecil. 240 ton produk yang harus diproses kembali merupakan keputusan yang sulit, tetapi ini merupakan alternatif terbaik karena kapasitas produksi tidak dapat diturunkan. Pembuatan fasilitas baru dianggap belum efektif karena permasalahan hanya pada periode tertentu dan waktu yang yang singkat. Metode linier programming mampu memberikan solusi terkait dengan minimasi biaya total yang berbentuk linier (Sukendar and Kristomi, 2008). Solusi yang optimal terkait dengan tingkat persediaan dalam inventori mampu meminimalkan biaya persediaan (Wahyuni and Singgih, 2005).
Langkah selanjutnya adalah membuat perencanaan kapasitas persediaan selama 12 hari. Perencanaan ini bertujuan untuk mengoptimalkan sistem persediaan dan penentuan produk yang akan diproses kembali. Berdasarkan pertimbangan bahwa 240 ton yang akan diproses kembali diambil dari 3 tangki awal. Pertimbangan ini diambil dengan mempertimbangkan lifetime produk. 3 tangki tersebut baru siap setelah hari ketiga dan reprocessed dilakukan pada hari keempat sampai kesembilan. Penentuan hari reprocessed dilakukan agar produk yang akan di reprocessed tidak tercampur dengan produk baru dan tangki bisa diisi kembali setelah reprocessed selesai (Gambar 2). 


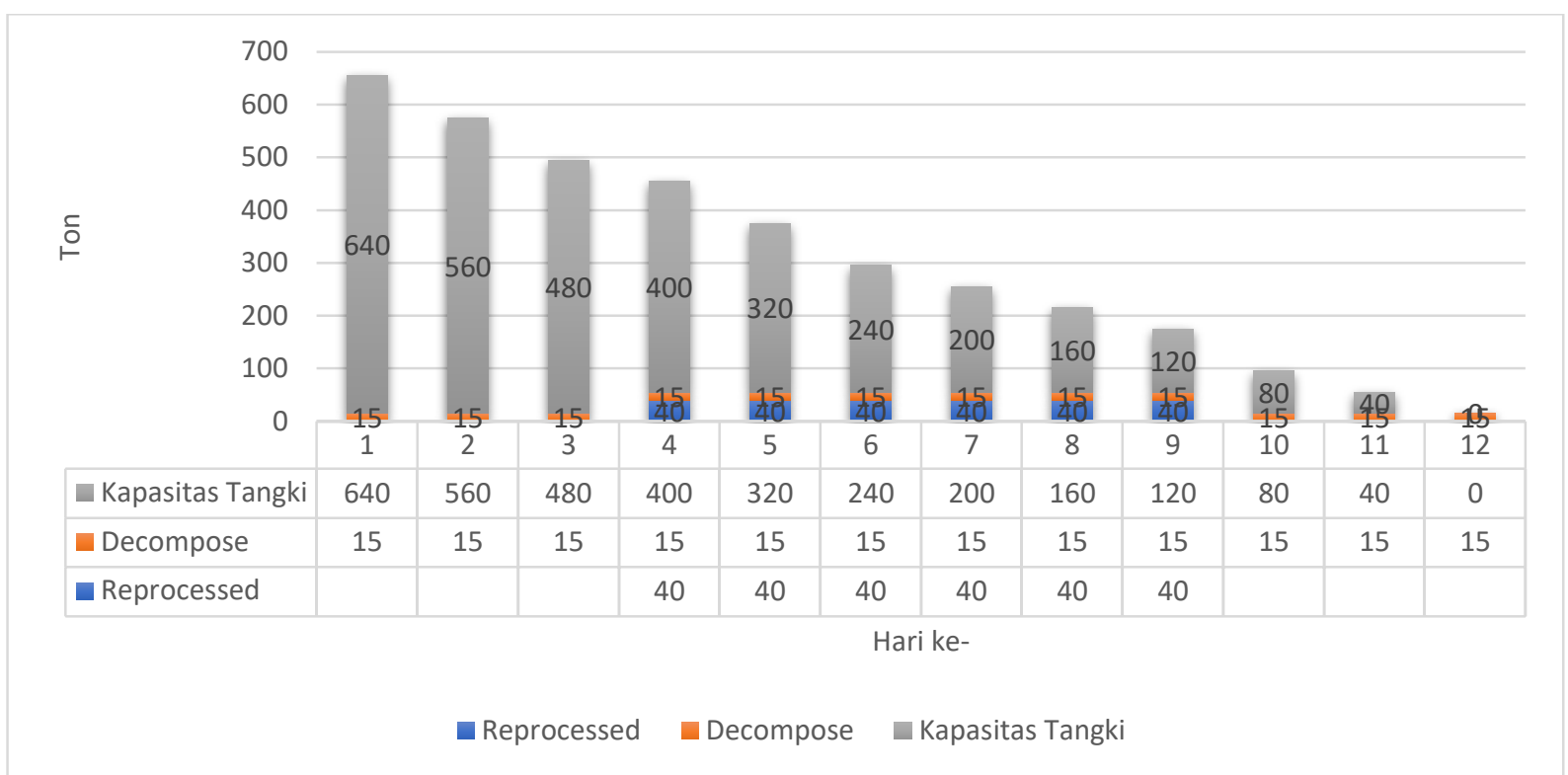

Gambar 2. Manajemen Inventori Selama 12 Hari

\section{KESIMPULAN}

Optimalisasi perencanaan tingkat persediaan produksi sodium hypochlorite $(\mathrm{NaClO})$ menggunakan metode linier programming adalah dengan mengoptimalkan pemakaian tangka yang mempunyai biaya terendah sebesar $\$ 2$. Pemanfaatan 8 tangki penyimpanan sebanyak 720 ton mampu meminimalkan produk yang harus diproses kembali sebanyak 240 ton. Sistem perencanaan ini mampu mengefektifkan biaya yang harus dikeluarkan sebesar $\$ 20280$. Proses reprocessed dapat diminimalkan dengan menjalin kerjasama dengan customer di sekitar perusahaan sehingga tetap dapat melakukan pengiriman sodium hypochlorite $(\mathrm{NaClO})$. Hal ini perlu dilakukan karena di kondisi normal perusahaan masih mengalami kekurangan persediaan untuk memenuhi kebutuhan customer. Penelitian ini bisa dilanjutkan dengan perencanaan agregat planning sehingga reprocessed dapat diminimalkan.

\section{DAFTAR PUSTAKA}

Aprilyanti, S., Pratiwi, I., and Basuki, M. (2018). Optimasi Keuntungan Produksi Kemplang Panggang Menggunakan Linear Programming Melalui Metode Simpleks. Seminar Dan Konferensi Nasional IDEC, 111. https://idec.ft.uns.ac.id/wpcontent/uploads/2018/05/ID038.pdf

Basriati, S. (2018). Integer Linear Programming Dengan Pendekatan Metode Cutting Plane dan Branch and Bound untuk Optimasi Produksi Tahu. Jurnal Sains Matematika Dan Statistika: Jurnal Hasil Penelitian Matematika, Statistika, Dan Aplikasinya, $4(2), \quad 95-104 . \quad$ http://ejournal.uin-
suska.ac.id/index.php/JSMS/article/view/62 03

Gultom, S. M., Bu'ulolo, F., and Sitepu, H. R. (2013). Penerapan Model Program Linier Primal-dual dalam Mengoptimalkan Produksi Minyak Goreng pada PT Xyz. Saintia Matematika, 1(1), 29-40. https://jurnal.usu.ac.id/index.php/smatemati $\mathrm{ka} /$ article/view/1016

Hasmi, R. A. (2018). Optimasi Perencanaan Produksi dengan Menggunakan Metode Linear Programming pada CV. Aceh Bakery. Jurnal Optimalisasi, 1(1), 44-56. http://www.jurnal.utu.ac.id/joptimalisasi/articl e/view/168

Kelvin, S., and Jobiliong, E. (2015). Optimasi Keuntungan Produk Helm PT Mega Karya Mandiri dengan Menggunakan Metode Linear Programming. Seminar Nasional Teknik Industri, 44-54. http://digilib.mercubuana.ac.id/manager/t!@ file_artikel_abstrak/Isi_Artikel_3518543491 86. pdf

Livia, C. Y. (2017). Usulan Penjadwalan Produksi untuk Meminimalkan Total Tardiness dengan Metode Integer Linear Programming Pada Bagian Produksi Printing PT Mitra Mulia Makmur. Jurnal Teknik Industri, 18(2), 127-137.

https://doi.org/10.22219/JTIUMM.Vol18.No2 .127-137

Rois, M. A. (2018). Metode Simpleks Program Linear pada Optimalisasi Pengelolaan Lahan Parkir FST UIN Walisongo dengan Konsep "Ukhuwah." Jurnal Mipa, 41(1), 5157. 
https://journal.unnes.ac.id/nju/index.php/JM/ article/view/16382

Saryoko, A. (2016). Metode Simpleks Dalam Optimalisasi Hasil Produksi. Informatics for Educators and Professional: Journal of Informatics, 1(1), 27-36. http://ejournalbinainsani.ac.id/index.php/ITBI/article/view/ 140

Sitinjak, T. J. R. (2006). Riset Operasi untuk Pengambilan Keputusan Manajerial dengan Aplikasi Excel. yogyakarta: Graha IImu

Stapleton, D. M., Hanna, J. B., and Markussen, D. (2003). Marketing strategy optimization: Using linear programming to establish an optimal marketing mixture. American Business Review, 21(2), 54-62. https://search.proquest.com/openview/fd0d 4e2512651c17613a2e92b74dc70e/1 ?pqorigsite $=$ gscholar $\& \mathrm{cbl}=31895$

Sukendar, I., and Kristomi, R. (2008). Metoda Agregat Planning Heuristik Sebagai Perencanaan dan Pengendalian Jumlah Produksi Untuk Minimasi Biaya. Prosiding Seminar Nasional Teknoin, 107-112. https://journal.uii.ac.id/Teknoin/article/view/2 102

Supriyadi, S., Muslimat, A., Pratama, R., and Ramayanti, G. (2017). Implementasi Linear Programming Untuk Memaksimalkan
Keuntungan. Prosiding Seminar Nasional Riset Terapan/ SENASSET, 183-189. https://e-

jurnal.Ippmunsera.org/index.php/senasset/a rticle/view/446

Wahyuni, C. E., and Singgih, M. L. (2005). Minimasi Biaya Produksi Tegel Menggunakan Pendekatan Linier Programming di Perusahaan Tegel CV. Penataran Blitar. Prosiding Seminar Nasional Manajemen Teknologi I, 1-9. http://mmt.its.ac.id/download/SEMNAS/SE MNAS I/Prosiding caroline -OK.pdf

Wassick, J. M., Agarwal, A., Akiya, N., Ferrio, J., Bury, S., and You, F. (2012). Addressing the operational challenges in the development, manufacture, and supply of advanced materials and performance products. Computers \& Chemical Engineering, 47, 157-169.

https://doi.org/10.1016/j.compchemeng.201 2.06.041

Wulandari, S. A., Defriyanto, D., and Suherman, S. (2019). Peran Linear Programming Metode Simpleks Dalam Mengoptimalisasi Keuntungan Pada Inovasi Bisnis Model. Inovasi Pembangunan: Jurnal Kelitbangan, $7(2)$, 197-204. 